\title{
Molecular prevalence of Chlamydia and Chlamydia-like bacteria in Tunisian domestic ruminant farms and their influencing risk factors
}

\author{
M. Barkallah ${ }^{1}$ \\ H. Jribi ${ }^{1}$ \\ A. Ben Slima ${ }^{1}$ \\ Y. Gharbi ${ }^{1}$ \\ Z. Mallek ${ }^{2}$ \\ M. Gautier ${ }^{3}$

\section{\begin{tabular}{l|l} 
I. Fendri & ${ }^{1}$ R. Gdoura $^{1}$
\end{tabular}}

${ }^{1}$ Faculty of Sciences of Sfax, ToxicologyMicrobiology and Environmental Health Laboratory (LR17ES06), University of Sfax, Sfax, Tunisia

${ }^{2}$ Veterinary Research Center of Sfax, Sfax, Tunisia

${ }^{3}$ Equipe Microbiologie de l'œuf et des Ovoproduits (MICOV), Agrocampus Ouest, INRA, (UMR1253) Science et Technologie du Lait et de l'OEuf, Rennes, France

\section{Correspondence}

I. Fendri, Faculty of Sciences of Sfax, Laboratory of Plant Biotechnology applied to the improvement of cultures, University of Sfax, Sfax, Tunisia.

Email: imenfendri1982@gmail.com

\section{Present addresses}

M. Barkallah, Unité de Biotechnologie des Algues, Biological Engineering Department, National School of Engineers of Sfax, University of Sfax, Sfax, Tunisia.

I. Fendri, Faculty of Science of Sfax, Laboratory of Plant Biotechnology applied to the improvement of cultures, University of Sfax, Sfax, Tunisia.

\section{Funding information}

Ministère de l'enseignement supérieur et de la recherche scientifique; ISESCO

Organization

\begin{abstract}
Summary
Chlamydia and Chlamydia-like bacteria are well known to infect several organisms and may cause a wide range of diseases, particularly in ruminants. To gain insight into the prevalence and diversity of these intracellular bacteria, we applied a panChlamydiales real-time PCR to 1,134 veterinary samples taken from 130 Tunisian ruminant herds. The true adjusted animal population-level prevalence was $12.9 \%$ in cattle, against $8.7 \%$ in sheep. In addition, the true adjusted herd-level prevalence of Chlamydiae was $80 \%$ in cattle and $25.5 \%$ in sheep. Chlamydiales from three familylevel lineages were detected indicating a high biodiversity of Chlamydiales in ruminant herds. Our results showed that Parachlamydia acanthamoebae could be responsible for bovine and ovine chlamydiosis in central-eastern Tunisia. Multivariable logistic regression analysis at the animal population level indicated that strata and digestive disorders variables were the important risk factors of bovine and ovine chlamydiosis. However, origin and age variables were found to be associated with bovine and ovine chlamydiosis, respectively. At the herd level, risk factors for Chlamydia positivity were as follows: abortion and herd size for cattle against breeding system, cleaning frequency, quarantine, use of disinfectant and floor type for sheep. Paying attention to these risk factors will help improvement of control programs against this harmful zoonotic disease.
\end{abstract}

KEYWORDS

Abortion, Chlamydiae, Coculture, sequencing, TaqMan PCR, veterinary samples

\section{1 | INTRODUCTION}

Tunisia is one of the leading countries in livestock production in Africa, with an estimated livestock population of more than 9.2 million head of ruminants (Zaibet, Hammami, \& Jabbar, 2009). The livestock sector is the second largest source of income, accounting for $35 \%$ of the agricultural gross domestic product. Beyond its macroeconomic importance, livestock farming occupies $8.8 \%$ of the working population. It contributes at $97 \%$ to the collective satisfaction of the population food needs. Despite its importance, food and sanitary problems hamper the development of this sector (Zaibet et al., 2009). Similarly, the poor diagnostic and epidemiological surveillance capacities of the veterinary services have resulted in a low rate of livestock health coverage (Zaibet et al., 2009). In addition, ruminants are exposed to several health problems, such as gastrointestinal parasitic and respiratory diseases (Akkari et al., 2014; Gharbi et al., 2013). Numerous pathogenic agents, including viruses, protozoa, fungi and bacteria, are already known to directly affect animal health and reproductive function (Yoo, 2010). Among these infectious agents, we note Chlamydia which is one of the 
most important bacterial agents, causing chlamydiosis in ruminant species.

Chlamydiosis is a zoonotic disease with a global occurrence (Krawiec, Piasecki, \& Wieliczko, 2015). It is usually caused in cattle by Chlamydia abortus, belonging to the Chlamydiaceae family. This bacterium is mainly involved in abortions and hypofertility in cattle. The abortion occurs during the third trimester of gestation, particularly in heifers during their first pregnancy. After the abortion, several factors cause the transmission of Chlamydiae to susceptible animals such as contact with infected foetuses, foetal membranes, vaginal discharge, uterine secretions and milk (Rodolakis, 2006). Chlamydia pecorum was also isolated from the digestive tract of cows clinically affected by reproductive disorders, conjunctivitis, mastitis and pulmonary inflammation (Ruhl et al., 2009). However, its zoonotic potential is still unknown (Berri, Rekiki, Sidi Boumedine, \& Rodolakis, 2009). Moreover, there are increasing evidences supporting the role of Chlamydia-related bacteria such as Waddlia chondrophila and Parachlamydia acanthamoebae in bovine abortion (Baud, Thomas, Arafa, Regan, \& Greub, 2007; Borel et al., 2007). Ovine chlamydiosis, also known as enzootic abortion of ewes (EAE), is principally caused by $C$. abortus. This infection is characterized by reduction in milk production and abortion or birth of weak lamb and can be transmitted by the same ways given in cattle (Barkallah et al., 2014). C. pecorum strains have also been associated with a variety of diseases in sheep including arthritis, conjunctivitis and enteric infections. Nevertheless, the involvement of $C$. pecorum in ovine abortion cases was also reported, almost 26 years ago, in southern France (Berri et al., 2009). Previous collaborative studies between veterinary institutes in Morocco, Algeria and Tunisia have confirmed the isolation of C. pecorum strains from abortion cases (Berri et al., 2009; Rekiki et al., 2004), suggesting the involvement of this bacterium in the spontaneous abortion of small ruminants in North African countries. To date, W. chondrophila has never been detected in cases of abortions in sheep. In contrast, authors showed that P. acanthamoebae was detected by molecular techniques and immunohistochemistry in aborted ewe placentas and in the lung of an aborted small lamb (Ruhl et al., 2009).

Many previous studies were conducted in different geographical regions of Tunisia and demonstrated the presence of antibodies against chlamydial species (Rekiki et al., 2004). However, there is still a gap of information on the existence of this infection in many parts of the country. This study aimed at (i) determining the true prevalence of Chlamydiae among ruminants in central-eastern Tunisia and (ii) identifying potential risk factors associated with chlamydial infection at the individual animal and herd levels.

\section{2 | MATERIALS AND METHODS}

\subsection{Ethical considerations}

The study protocol was assessed and approved by the institutional review board (IRB) of the Regional Office of Agricultural Development of Sfax (CRDA) in collaboration with the Veterinary Research Center of Sfax in Tunisia. All breeders declared their verbal and written consent before animal sampling as well as for the related survey questions. Samples were collected by authorized veterinarians of the
Veterinary Research Center of Sfax during annual vaccination campaigns following standard procedures of the usual screening scheme on farms and Tunisian ethical guidelines.

\section{2 | Study area, animals and samples}

This study was conducted in Sfax town (average altitude of $13 \mathrm{~m}$ ), which is located in the East Centre of Tunisia, at $270 \mathrm{~km}$ from the capital Tunis. During this study, many geographical regions of Sfax have been visited as described by Barkallah et al. (2017). In each region, households owning cattle and/or sheep were identified through discussion with responsible veterinarians during the annual vaccination campaigns. The number of herds to be studied was calculated using the following formula $n=\left[t^{2}\right.$ Pexp (1-Pesp) $] / d^{2}$ as previously described by Barkallah et al. (2017). In total, 20 Holsteins bovine herds and 110 ovine herds were visited. Blood, vaginal swabs and milk samples were collected from 378 animals and sent to the laboratory. These samples were collected as described by Barkallah et al. (2016).

\section{3 | Epidemiological data collection}

Two detailed questionnaires were used separately to collect information on potential management and environmental risks factors related to bovine and ovine chlamydiosis at the individual animal and herd levels. The owners of ruminants were questioned by the principal researcher of this study.

\subsection{Cocultivation of Waddlia chondrophila in amoebae}

Fresh swab samples positive by real-time PCR were used to isolate W. chondrophila in the coculture system. In fact, $500 \mu \mathrm{l}$ of culture was taken from each swab and filtered through $0.22-\mu \mathrm{m}$ pore size membrane. Each membrane was then shaken in $500 \mu \mathrm{l}$ of Page's amoeba saline (PAS). Amoebae (strain Acanthamoeba castellanii ATCC 30010) were grown and prepared for culture as described by Lienard and Greub (2011). For inoculation, homogenized samples were inoculated into the wells by spinoculation at $2,000 \mathrm{~g}$ for $10 \mathrm{~min}$. Then, cocultures were examined to exclude or confirm the growth of W. chondrophila (Goy, Croxatto, Posfay-Barbe, Gervaix, \& Greub, 2009).

\subsection{DNA extraction}

DNA from all blood, milk and vaginal swab samples was extracted by ZR Fungal/Bacterial DNA MiniPrep ${ }^{\mathrm{TM}}$ D6005 Kit (Zymo Research) as described by Barkallah et al. (2016).

\subsection{Chlamydiales-specific real-time PCR}

A pan-Chlamydiales real-time PCR that may amplify all members of the Chlamydiales order was performed as described previously by 
Lienard, Croxatto, Aeby, Jaton, and Posfay-Barbe (2011). The detection limit of this assay was five DNA copies per reaction of the positive control (with an efficiency of 75\%). The amplified products were sent to GATC Biotech SARL (Germany) for sequencing. Sequences were compared, with the BLAST server, to existing sequences on GenBank which classifies them based on the percentage identity of the best known species. Positive samples for W. chondrophila and $P$. acanthamoebae were quantified using previously described realtime PCRs (Casson, Posfay-Barbe, Gervaix, \& Greub, 2008; Goy et al., 2009). Both PCR assays were able to detect bacterial DNA over a linear range of $10-10^{7}$ copies per reaction mixture. However, C. abortus and C. pecorum were quantified in veterinary samples using two commercial kits "PrimerDesign ${ }^{\mathrm{TM}}$ genesig Kits for $C$. abortus and C. pecorum genomes quantification" (Genesig). Both assays could detect DNA to levels less than 10 copies/ $\mu$ l (Pantchev, Sting, Bauerfeind, Tyczka, \& Sachse, 2010).

\section{7 | Statistical analysis}

The true prevalence (TP) of chlamydial infection at the individual animal level was estimated using Epitools epidemiological calculators (http://epitools.ausvet.com.au/content.php?page=home) and the following formula: $\mathrm{TP}=(\mathrm{AP}+\mathrm{Sp}-1) /(\mathrm{Se}+\mathrm{Sp}-1) \quad($ Rogan \& Gladen, 1978). Herd-level prevalence was calculated as the number of herds with at least one positive animal divided by the total number of herds tested. The true herd prevalence (THP) was estimated from distributions of herd sensitivity (HSe) and specificity (HSp) as described by Christensen and Gardner (2000).

The risk factor analysis was separately performed at the animal and herd levels for cattle and sheep as described by Barkallah et al. (2016). The overall goodness of fit of final models was assessed using Pearson's chi-square and Hosmer-Lemeshow tests (Hosmer \& Lemeshow, 1980).

\section{3 | RESULTS}

\section{1 | Detection of Chlamydiae}

For bovine samples, chlamydial DNA was detected in 27/214 (12.61\%) vaginal swab samples. To know the responsible species of infection, PCR products were sequenced and analysed using the BLAST web interface (http://blast.ncbi.nlm.nih.gov/Blast.cgi). Among the $16 \mathrm{~S}$ rRNA sequences of these 27 test-positive samples, 12, 8 and 7 sequences with hits in the BLAST analysis belonged to Waddliaceae, Parachlamydiaceae and Chlamydiaceae families, respectively (Barkallah et al., 2014). No chlamydial DNA was detected in milk and blood samples. All amoebal cocultures $(n=12)$ remained negative for W. chondrophila.

For ovine samples, chlamydial DNA was detected only in 14/164 (8.53\%) vaginal swab samples. The amplicon sequences of four testpositive samples were found to be $99 \%$ identical to the $P$. acanthamoebae $16 \mathrm{~S}$ rDNA gene in the database. All of them had already been confirmed by the P. acanthamoebae-specific PCR-TR-TaqMan as previously described (Casson et al., 2008). Five among the 10 remaining sequences belonging to the Chlamydiacaeae family demonstrated $\geq 99 \%$ sequence similarity with $C$. abortus, whereas the remaining sequences exhibited $\geq 99 \%$ sequence similarity with $C$. pecorum. These results were confirmed by two commercial kits specific for the quantification of $C$. abortus and C. pecorum. As for cattle, a very high bacterial load was found in the ovine vaginal samples (35-1434 copies/ $\mu$ l). All milk and blood samples were shown to be negative.

\section{2 | Prevalence of chlamydial infection}

The apparent individual animal prevalence (AP) of chlamydial infection in cattle $(12.61 \%$; $95 \% \mathrm{Cl}: 8.82 \%-17.73 \%)$ was found higher than in sheep (8.54\%; 95\% Cl: 5.15\%-13.82\%) ( $Z$ test: $p=.101)$. Sixteen of 20 (80\%; 95\% Cl [65.2\%-94.7\%]) bovine herds had at least one positive animal for Chlamydia. Compared with sheep, an overall $12.7 \%$ (14/110) (95\% Cl [7.48\%-17.92\%]) herd-level prevalence of chlamydial infection was found ( $Z$ test: $p<.0001$ ). The AP of chlamydial infection on both individual animal and herd levels was adjusted to the sensitivity (97.7\%) and specificity (100\%) of the panChlamydiales PCR (Lienard et al., 2011). In cattle, the true prevalence (TP) at the animal level was $12.9 \%(95 \% \mathrm{Cl}$ : [8.4\%-17.5\%]), against 8.7\% (95\% Cl: [4.4\%-13.1\%]) in sheep. The average number of animals tested in each herd of cattle was 10 , while for sheep, the number was shown to be between 1 and 5 animals, according to the herd/flock sizes. Therefore, the herd specificity (HSp) was equal to 1 for the two species of ruminants. For cattle, the herd sensitivity (HSe) was $1-(1-0.8)^{10}=0.9999$, while for sheep, it was 1 - (1 $0.127)^{5}=0.5$. According to these calculated parameters, the THP of chlamydial infection was equal to $80 \%$ for cattle and $25.5 \%$ for sheep.

\subsection{Univariable analysis of related risk factors}

At the individual animal level, four variables (age range, strata, abortion and digestive disorders) were found to be significantly associated with chlamydial infection in cattle $(p<.05)$ (Table 1). However, the variables (age range, abortion, conjunctivitis and digestive disorders) were significantly associated with chlamydial infection in sheep (Table 1).

At the herd level, all risk factors assumed to be associated with chlamydial infection in cattle and sheep are presented in Table 2. All significant and non-significant variables $(p<.2)$ were then entered to the multivariable logistic analysis (Table 2 ).

\section{4 | Multivariable logistic regression analysis}

The Hosmer-Lemeshow goodness of fit test indicated adequate fit for both the cattle $(p=.639)$ and the sheep $(p=.772)$ models (Table 3). From the final model for cattle, it can be seen that the odds of Chlamydia positivity were significantly higher in homebred cows compared to purchased cows with an OR of $3(p=.032)$. We 
TABLE 1 Potential risk factors associated with individual animal level Chlamydia positivity among 214 cows and 164 ewes

\begin{tabular}{|c|c|c|c|c|c|c|c|}
\hline \multirow[b]{2}{*}{ Variable and level } & \multicolumn{3}{|l|}{ Cattle } & \multirow[b]{2}{*}{ Variable and level } & \multicolumn{3}{|l|}{ Sheep } \\
\hline & No. of animals & No. of positive (\%) & $p$-Value & & No. of animals & No. of positive (\%) & $p$-Value \\
\hline Age range & & & & Age range & & & \\
\hline $3-5$ & 74 & 9 (12.16) & & $2-3$ & 81 & $12(14.8)$ & \\
\hline$>5$ & 20 & $7(35)$ & & & & & \\
\hline Rural & 9 & 1 (11.11) & .049 & Rural & 40 & $6(15)$ & .236 \\
\hline Peri-urban & 76 & $4(5.26)$ & & Peri-urban & 83 & $5(6)$ & \\
\hline Urban & 129 & $22(17)$ & & Urban & 41 & $3(7.3)$ & \\
\hline Origin & & & & Origin & & & \\
\hline Home bred & 85 & $12(14.11)$ & .591 & Home bred & 130 & $9(6.9)$ & .148 \\
\hline No & 64 & $0(0)$ & & No & 64 & $0(0)$ & \\
\hline Conjunctivitis & & & & Conjunctivitis & & & \\
\hline Yes & 7 & $1(14.2)$ & .892 & Yes & 8 & $3(37.5)$ & .003 \\
\hline No & 207 & $26(12.5)$ & & No & 156 & $11(7.1)$ & \\
\hline Digestive disorders & & & & Digestive disorders & & & \\
\hline Yes & 43 & $12(27.9)$ & $<.001$ & Yes & 29 & $10(34.48)$ & $<.001$ \\
\hline No & 171 & 15 (8.77) & & No & 135 & $4(2.96)$ & \\
\hline Respiratory disorders & & & & Breed & & & \\
\hline Yes & 6 & 2 (33.3) & .297 & Barbarine & 144 & $11(9.7)$ & .27 \\
\hline
\end{tabular}

noted also that the risk of Chlamydia positivity was 6.18 times higher in affected cows by digestive disorders than in healthy cows $(p<.001)$. For sheep between 2 and 3 years old, the odds of Chlamydia positivity were 166 times higher compared with those that are 1 year of age. We also noted that the risk of Chlamydia positivity was 65 and 143 times higher in rural than in urban and periurban areas (Table 3). In addition, the risk of Chlamydia test positivity was significantly higher in ewes affected by digestive disorders compared to the healthy ones (OR $=35.71 ; p<.001)$.

At the herd level, risk factors associated with Chlamydia positivity in the multivariable logistic regression analysis were as follows: abortion and herd size for cattle against breeding system, handling, cleaning frequency, floor type and use of disinfectant for sheep. The Hosmer-Lemeshow test showed that the two final models fit well the data for the cattle herds $(p=.8)$ and sheep flocks $(p=.963)$ (Table 4).

\section{DISCUSSION}

In the diagnosis of chlamydiosis, which it is connected with surveillance investigations of the disease in ruminants, different types of methods are used. The choice of a diagnostic method largely depends on the type and number of samples to be tested and the stage of infection in animals. Since serological and traditional culture techniques are ineffective, the pan-Chlamydiales real-time PCR was chosen for mass screening because is robust, rapid, sensitive and highly specific (Lienard et al., 2011). In addition, this real-time PCR could detect low concentrations of chlamydial DNA from various types of samples (Lienard et al., 2011).

Based on the present study results, Chlamydia and Chlamydia-like microorganisms do not seem to be excreted in the milk of ruminants. This is in accordance with the results of other studies showing that an infected ruminant does not necessarily excrete Chlamydia in milk and, if so, it may be irregular (Thomas, Davison, \& Wilsmore, 1990). Thus, our results confirm that milk is not the best sample to detect chlamydial DNA, a statistically significant and clinically important finding. The low incidence of Chlamydia in blood samples can be explained by the low chlamydial load particularly in cases of chronic chlamydiosis.

The Chlamydiaceae family is frequently found in domestic ruminant herds and generally associated with reproductive problems (Merdja et al., 2015). Thus, it is not surprising that 17 of the 41 positive PCRs performed on vaginal swab samples were positive for 
TABLE 2 Analysis of potential risk factors associated with herd-level prevalence of chlamydial infection in ruminants from different geographical regions of Sfax in Tunisia

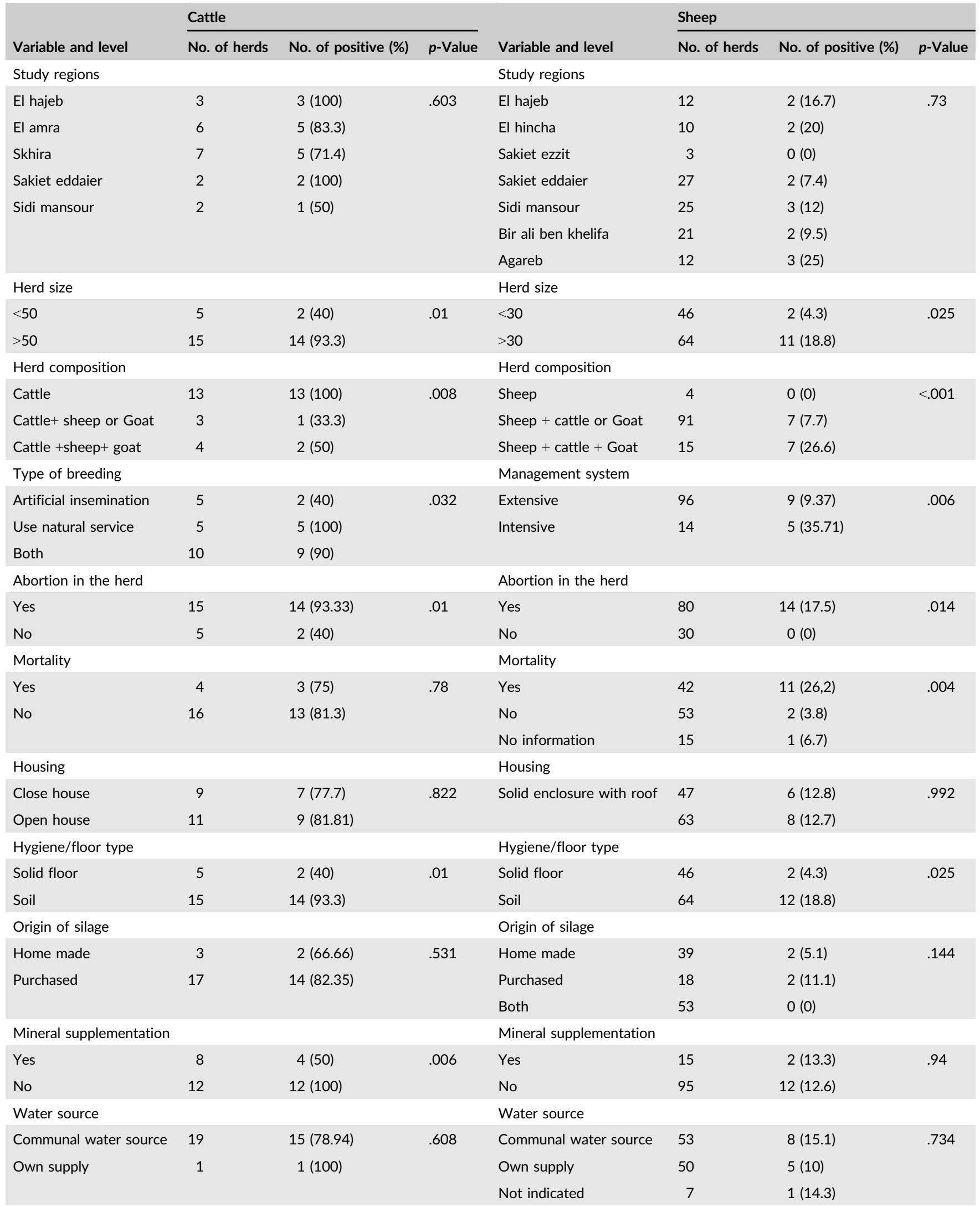


TABLE 2 (Continued)

\begin{tabular}{|c|c|c|c|c|c|c|c|}
\hline \multirow[b]{2}{*}{ Variable and level } & \multicolumn{3}{|l|}{ Cattle } & \multirow[b]{2}{*}{ Variable and level } & \multicolumn{3}{|l|}{ Sheep } \\
\hline & No. of herds & No. of positive (\%) & $p$-Value & & No. of herds & No. of positive (\%) & $p$-Value \\
\hline \multicolumn{4}{|c|}{ Herd prophylactic measures ${ }^{a}$} & \multicolumn{4}{|c|}{ Herd prophylactic measures ${ }^{a}$} \\
\hline No & 6 & $3(50)$ & & No & 67 & $12(17.9)$ & \\
\hline \multicolumn{4}{|l|}{ Cleaning frequency } & \multicolumn{4}{|l|}{ Cleaning frequency } \\
\hline Monthly & 4 & $4(100)$ & & Monthly & 13 & $3(23.1)$ & \\
\hline No cleaning & 1 & $1(100)$ & & No cleaning & 12 & $4(33.3)$ & \\
\hline \multicolumn{4}{|l|}{ Use of disinfectant } & \multicolumn{4}{|l|}{ Use of disinfectant } \\
\hline Yes & 12 & $8(66.7)$ & .068 & Yes & 16 & $4(25)$ & .111 \\
\hline No & 8 & $8(100)$ & & No & 94 & $10(10.6)$ & \\
\hline \multicolumn{4}{|l|}{ Handling } & \multicolumn{4}{|l|}{ Handling } \\
\hline Quarantined & 11 & 7 (63.6) & .043 & Quarantined & 54 & $3(5.6)$ & .027 \\
\hline Mixed & 9 & $9(100)$ & & Mixed & 56 & $11(19.6)$ & \\
\hline \multicolumn{4}{|c|}{ Breeder Knowledge of Chlamydiosis } & \multicolumn{4}{|c|}{ Breeder Knowledge of Chlamydiosis } \\
\hline Yes & 2 & $1(50)$ & .264 & Yes & 11 & $1(9.1)$ & .703 \\
\hline No & 18 & 15 (83.3) & & No & 99 & $13(13.1)$ & \\
\hline \multicolumn{4}{|c|}{ Socio-economic status of farmer } & \multicolumn{4}{|c|}{ Socio-economic status of farmer } \\
\hline Full-time & 5 & $4(80)$ & .392 & Full-time & 98 & $11(11.2)$ & .401 \\
\hline Yes & 1 & $1(100)$ & .608 & & & & \\
\hline No & 19 & $15(78.94)$ & & & & & \\
\hline
\end{tabular}

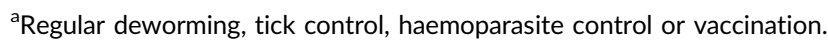

${ }^{b}$ Veterinarian or livestock assistant attending to the ruminants.

${ }^{\mathrm{c}}$ Regular or occasional rectal palpation or gynaecological/obstetrical examination.

Chlamydiaceae. The high prevalence of positivity (60\%) for Parachlamydiaceae is important to investigate in our case as $P$. acanthamoebae, a species of this chlamydial family, is well known to cause reproductive disorders, especially in cattle (Barkallah et al., 2014; Borel et al., 2007). In our study, 12 samples from five ruminant herds were positive for P. acanthamoebae. This is the first description of this Chlamydia-like bacterium in ovine abortion in African farms. W. chondrophila was absent in all ovine samples tested in our study. This result is in agreement with those of a previous study showing the non-susceptibility of ewes to be infected with W. chondrophila. Recently, an in vitro study has shown that W. chondrophila is able to infect and multiply in ovine trophoblastic cells while inducing an immune and inflammatory response in a dose-dependent way similar to that observed with C. abortus (Wheelhouse et al., 2014). More samples should be collected to survey the reproductive problems caused by this chlamydia-like bacterium in Tunisian sheep flocks.

At the individual animal level, our results concerning both bovine and ovine chlamydiosis are highly consistent with those observed in other studies realized in Tunisia (Zaibet et al., 2009) and Zambia (Ghirotti et al., 1991) and in other continents (Blumer, Greub, Waldvogel, Hassig, \& Thoma, 2011; Szymańska-Czerwińska, Niemczuk, \& Galińska, 2013). At the herd level, our AP data are proportionally similar to those described in other studies realized in Switzerland (Borel et al., 2004), Germany (Lenzko et al., 2011), Ireland (Wilson et al., 2012) and in Algeria (Merdja et al., 2015). The adjustment of prevalence according to the performance of the used molecular test gave TP values of $12.9 \%$ in cattle and $8.7 \%$ in sheep. The TP value of chlamydial infection in sheep was higher than those obtained in other studies carried out in other governorates of Tunisia 
TABLE 3 Final model of animal population-level risk factors associated with chlamydial infection among cattle and sheep

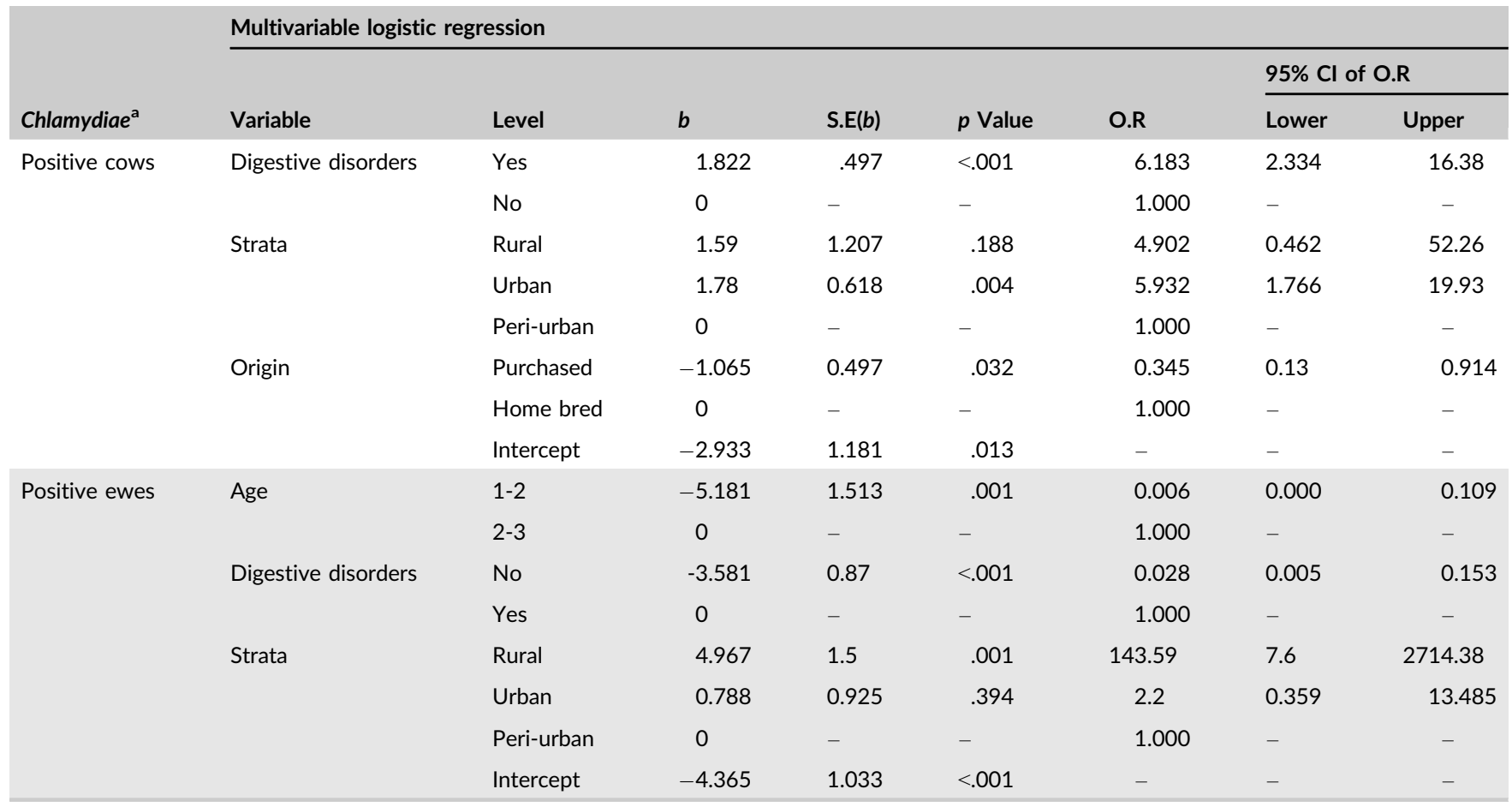

${ }^{\text {a }}$ The reference category is negative.

TAB LE 4 Risk factors for herd-level chlamydial infection in 130 ruminant herds in different regions of Sfax, Tunisia: results of a multiple logistic regression model

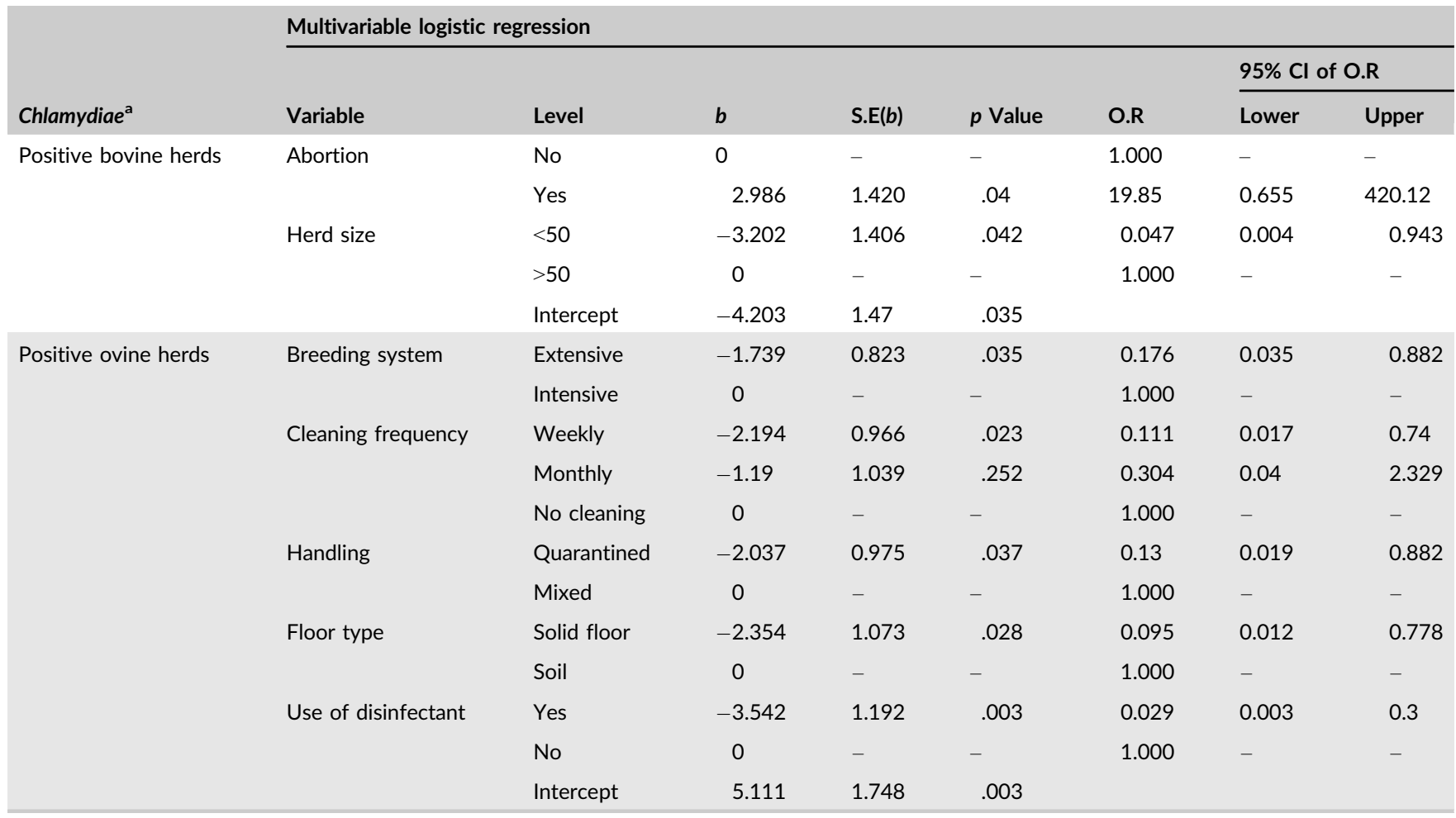

${ }^{\text {a }}$ The reference category is negative.

(Elandalousi, Ghram, Maaroufi, \& Mnif, 2015; Zaibet et al., 2009). The signalled high prevalence of chlamydial infection of $37.16 \%$ in cattle of Kalaat El Andalous (northern Tunisia) could be due to the specificity lack of some serological techniques based on chlamydial antigen preparations and purified chlamydial LPS (Elandalousi et al., 2015). At the herd level, the TP of chlamydial infection in sheep 
(80\%) was higher than those reported in Tunisia (6.25\%) (Zaibet et al., 2009), in Zaer and Morocco (21.5\%) (Hamzy-El Idrissi, Manyari, \& Benkirane, 1995) and in Mauritania (20\%) (Chartier \& Chartier, 1988). In fact, all these investigations were based only on Chlamydiaceae-specific serological tests, and therefore, infected animals with Chlamydia-like bacteria were not considered. In addition, the changing of diagnostic techniques and the choice of sampling methods are important factors that contribute to the variability of results among investigations. On the other hand, Rekiki et al. (2004) reported a relatively similar prevalence rate of $26 \%$ in Tunisian sheep flocks.

Several reports agree with the fact that the risk of transmission of Chlamydiae in cattle varied significantly depending on the strata and the involved systems of production (Igayara-Souza, Genovez, Ferreira, Paulin, \& Scarcelli, 2004; Jaouad, 2004). Our results have shown that the probability of having a positive animal was higher in urban (17\%) than in peri-urban $(5.26 \%)$ and rural (11.1\%) areas. This could be explained by the fact that most dairy farmers practicing the intensive farming are situated in urban areas where there is a high demand for milk (Barkallah et al., 2017; Jaouad, 2004). In this type of areas, reproductive infections associated with Chlamydiae, particularly abortions, appear mainly as enzootic diseases, resulting in severe economic losses (Igayara-Souza et al., 2004). On the other hand, the risk of chlamydial infection in sheep was equal in urban and rural areas, where keeping sheep is a method to save money. The observed association between Chlamydia status and the ruminant's age was consistent with what is mostly known about the biology of infection (Qin et al., 2014; Zhou et al., 2013). This association with aged animals may be due to (i) the cumulative probability of exposure to Chlamydiae (Qin et al., 2014) and (ii) the immune system failure (Zhou et al., 2013). Similarly, the observed relationships between chlamydial infection and abortive and digestive disorders were consistent with what has generally been observed (Longbottom et al., 2013; Merdja et al., 2015; Wheelhouse et al., 2014). Under these conditions, the infection finds favourable ground for transmission through placental and foetal membranes, faeces and urines (Barkallah et al., 2014). In addition, conjunctivitis was found to be a major risk factor significantly associated with chlamydial infection in sheep. These results are in agreement with those of other recent studies (Jelocnik et al., 2014; Polkinghorne et al., 2009).

As expected, different herd/flock properties were significantly associated with the probability of a herd/flock being positive. Our results showed that the risk of contracting Chlamydia increases significantly with the herd size. These results are in agreement with those of other studies, who observed that the prevalence of chlamydial infection was higher in herds with large numbers of animals (AlQudah, Sharif, Raouf, Hailat, \& AL-Domy, 2004; Merdja et al., 2015). In general, larger herds might be expected to be associated with intensive management practices that are characteristically more difficult to control and let for closer contact between susceptible and infected animals. Similarly, our findings showed that herd composition was linked to Chlamydiae test positivity. This finding is in accordance with those of Zaibet et al. (2009), who reported that the risk of chlamydial infection in sheep is multiplied by 4 and 1.08 in the presence of cattle and goats in the same farm. We also found that flocks exposed to Chlamydiae showed not only risks of abortions, but also high sheep mortality rates. Indeed, chlamydial infection induces high animal mortality that finally reduces the financial capital of breeders and increases costs of production (Hireche et al., 2014). The reduction in mortality and abortion rates requires that chlamydial infection be combated through divers management and sanitation practices such as the use of artificial insemination, the addition of mineral supplements and the installation of suitable prophylactic measures and animal quarantine services (Longbottom et al., 2013; Müller, Sachse, Kemmerling, Rietz, \& Sauerwein, 2013; Ostermann et al., 2013). All these applications play a crucial role in keeping the immune status of the herds healthy and may evenly give an indication of top herd management. Concerning the floor type, our results showed that the exposure risk to chlamydial infection was more important in ruminants in direct contact with soil than in those that are in contact with solid ground. These results corroborate those of several other authors, who showed that the soil could be a source of contaminated residues (Coulon et al., 2012; KebbiBeghdadi \& Greub, 2014).

Chlamydiosis is endemic at great levels in domestic ruminants in central-eastern Tunisia. The infection is heterogeneously distributed, with some farms at high risk as a result of practices such as the introduction of new animals without quarantine, changing of rams for reproduction and the intensification of the production system. The adoption of hygiene and biosecurity practices is recommended as a control strategy of chlamydial infection in Tunisian farms.

\section{ACKNOWLEDEGMENTS}

This project received financial support from "Ministère de l'enseignement supérieur et de la recherche scientifique" and the ISESCO Organization. The funders had no role in study design, data collection and analysis, decision to publish or preparation of the manuscript.

\section{CONFLICT OF INTEREST}

The authors declare that there are no conflict of interests.

\section{ORCID}

M. Barkallah iD http://orcid.org/0000-0001-8934-5731

\section{REFERENCES}

Akkari, H., Rtibi, K., B'chir, F., Rekik, M., Darghouth, M.A., \& Gharbi, M. (2014). In vitro evidence that the pastoral Artemisia campestris species exerts an anthelmintic effect on Haemonchus contortus from sheep. Veterinary Research Communications, 38(3), 249-255. https://d oi.org/10.1007/s11259-014-9609-y 
Al-Qudah, K. M., Sharif, L. A., Raouf, R. Y., Hailat, N. Q., \& AL-Domy, F. M. (2004). Seroprevalence of antibodies to Chlamydophila abortus shown in Awassi sheep and local goats in Jordan. Veterinarni Medicina, 49, 460-466.

Barkallah, M., Gharbi, Y., Hassena, A. B., Slima, A. B., Mallek, Z., Gautier, M., ... Fendri, I. (2014). Survey of infectious etiologies of bovine abortion during mid- to late gestation in dairy herds. PLOS ONE, 9(3), e91549. https://doi.org/10.1371/journal.pone.0091549

Barkallah, M., Gharbi, Y., Hmani, M., Mallek, Z., Gautier, M., Gdoura, R., \& Fendri, I. (2016). Locked nucleic acid probe-based real-time PCR for the diagnosis of Listeria monocytogenes in ruminants. Molecular and Cellular Probes, 30(3), 138-145. https://doi.org/10.1016/j.mcp.2016. 02.010

Barkallah, M., Gharbi, Y., Zormati, S., Karkouch, N., Mallek, Z., Gautier, M., ... Fendri, I. (2017). A mixed methods study of ruminant brucellosis in central-eastern Tunisia. Tropical Animal Health and Production, 49(1), 39-45. https://doi.org/10.1007/s11250-016-1155-x

Baud, D., Thomas, V., Arafa, A., Regan, L., \& Greub, G. (2007). Waddlia chondrophila, a potential agent of human fetal death. Emerging Infectious Diseases, 13, 1239-1243. https://doi.org/10.3201/eid1308. 070315

Berri, M., Rekiki, A., Sidi Boumedine, K., \& Rodolakis, A. (2009). Simultaneous differential detection of Chlamydophila abortus, Chlamydophila pecorum and Coxiella burnetii from aborted ruminant's clinical samples using multiplex PCR. BMC Microbiology, 9, 130. https://doi.org/10. 1186/1471-2180-9-130

Blumer, S., Greub, G., Waldvogel, A., Hassig, M., \& Thoma, R. (2011). Waddlia, Parachlamydia and Chlamydiaceae in bovine abortion. Veterinary Microbiology, 152(3-4), 385-393. https://doi.org/10.1016/j.vet mic.2011.05.024

Borel, N., Doherr, M. G., Vretou, E., Psarrou, E., Thoma, R., \& Pospischil, A. (2004). Seroprevalences for ovine enzootic abortion in Switzerland. Preventive Veterinary Medicine, 65(3-4), 205-216. https://doi.org/10. 1016/j.prevetmed.2004.08.005

Borel, N., Ruhl, S., Casson, N., Kaiser, C., Pospischil, A., \& Greub, G. (2007). Parachlamydia spp. and related Chlamydia-like organisms and bovine abortion. Emerging Infectious Diseases, 13, 1904-1907. https://doi.org/10.3201/eid1312.070655

Casson, N., Posfay-Barbe, K. M., Gervaix, A., \& Greub, G. (2008). New diagnostic real time PCR for specific detection of Parachlamydia acanthamoebae DNA in clinical samples. Journal of Clinical Microbiology, 46 (4), 1491-1493. https://doi.org/10.1128/JCM.02302-07

Chartier, C., \& Chartier, F. (1988). Enquête séro-épidémiologique sur les avortements infectieux des petits ruminants en Mauritanie. Revue d'élevage et Médecine Vétérinaire des Pays Tropicaux, 41, 23-34.

Christensen, J., \& Gardner, I. A. (2000). Herd-level interpretation of test results for epidemiologic studies of animal diseases. Preventive Veterinary Medicine, 45, 83-106. https://doi.org/10.1016/S0167-5877(00) 00118-5

Coulon, C., Eterpi, M., Greu, G., Collignon, A., McDonnell, G., \& Thomas, V. (2012). Amoebal host range, host-free survival and disinfection susceptibility of environmental Chlamydiae as compared to Chlmydia trachomatis. FEMS Immunology and Medical Microbiology, 64(3), 364 373. https://doi.org/10.1111/j.1574-695X.2011.00919.x

Elandalousi, R. B., Ghram, A., Maaroufi, A., \& Mnif, W. (2015). Séroprévalence des maladies abortives zoonotiques chez les ruminants au nord de la Tunisie. Research, fr, 2, 1419.

Gharbi, M., Zribi, L., Jedidi, M., Chakkhari, H., Hamdi, S., R'hayem, S., ... Darghouth, M.A. (2013). Prevalence of Toxoplasma gondii infection in Tunisian sheep. Bulletin de la Société de Pathologie Exotique, 106(3), 184-187. https://doi.org/10.1007/s13149-013-0290-4

Ghirotti, M., Semproni, G., De Meneghi, D., Mungaba, F.N., Nannini, D., Calzetta, G., \& Paganico, G. (1991). Sero-prevalences of selected cattle diseases in the Kafue flats of Zambia. Veterinary Research Communications, 15, 25-36. https://doi.org/10.1007/BF00497787
Goy, G., Croxatto, A., Posfay-Barbe, K. M., Gervaix, A., \& Greub, G. (2009). Development of a real-time PCR for the specific detection of Waddlia chondrophila in clinical samples. European Journal of Clinical Microbiology and Infectious Diseases, 28, 1483-1486. https://doi.org/ 10.1007/s10096-009-0804-7

Hamzy-El Idrissi, A., Manyari, A., \& Benkirane, A. (1995). Fréquence des avortements infectieux des ovins au Maroc (régions des Zaer et du Moyen Atlas). Actes de I'Institut Agronomique Vétérinaire, 15(4), 11 14.

Hireche, S., Bouaziz, O., Djenna, D., Boussena, S., Aimeur, R., Kabouia, R., $\&$ Bererhi, E. (2014). Seroprevalence and risk factors associated with Chlamydophila spp. infection in ewes in the northeast of Algeria. Tropical Animal Health and Production, 46, 467-473. https://doi.org/ 10.1007/s11250-013-0515-z

Hosmer, D. W., \& Lemeshow, S. (1980). Goodness-of-fit tests for the multiple logistic regression model. Communications in Statistics - Theory and Methods, 10, 1043-1069. https://doi.org/10.1080/ 03610928008827941

Igayara-Souza, C. A., Genovez, M. E., Ferreira, F., Paulin, L. M., \& Scarcelli, E. (2004). Ocorrência de anticorpos anti-Chlamydophila abortus em bovinos e avaliação de possível relação com distúrbios reprodutivos em São Paulo-Brasil. Revista brasileira de reprodução animal, 28 (1), 28-33.

Jaouad, M. (2004). Dynamique des cheptels bovins en Tunisie et contraintes alimentaires et fourragères. In Ferchichi, A, Réhabilitation des pâturages et des parcours en milieux méditerranéens. Zaragoza: CIHEAM. Options Méditerranéennes, 62, 421-424.

Jelocnik, M., Walker, E., Pannekoek, Y., Ellem, J., Timms, P., \& Polkinghorne, A. (2014). Evaluation of the relationship between Chlamydia pecorum sequence types and disease using a species-specific multi-locus sequence typing scheme (MLST). Veterinary Microbiology, 174(1-2), 214-222. https://doi.org/10.1016/j.vetmic.2014.08.018

Kebbi-Beghdadi, C., \& Greub, G. (2014). Importance of amoebae as a tool to isolate amoeba resisting microorganisms and for their ecology and evolution: The Chlamydia paradigm. Environmental Microbiology Reports, 6(4), 309-324. https://doi.org/10.1111/1758-2229.12155

Krawiec, M., Piasecki, T., \& Wieliczko, A. (2015). Prevalence of Chlamydia psittaci and Other Chlamydia Species in Wild Birds in Poland. Vector Borne Zoonotic Diseases, 15(11), 652-655. https://doi.org/10.1089/vb z.2015.1814

Lenzko, H., Moog, U., Henning, K., Lederbach, R., Diller, R., Menge, C., ... Sprague, L. D. (2011). High frequency of chlamydial co-infections in clinically healthy sheep flocks. BMC Veterinary Research, 7, 29. https://doi.org/10.1186/1746-6148-7-29

Lienard, J., Croxatto, A., Aeby, S., Jaton, K., \& Posfay-Barbe, K. (2011). Development of a new Chlamydiales-specific real-time PCR and its application to respiratory clinical samples. Journal Clinical Microbiology, 49(7), 2637-2642. https://doi.org/10.1128/JCM.00114-11

Lienard, J., \& Greub, G. (2011). Discovering new pathogens: Amoebae as tools to isolate Amoeba-resisting Microorganisms from environmental samples. In K.S.a.N.J., Ashbolt. (Ed.), Environmental Microbiology: Current technology and water applications. pp. (143-162) Norfolk, 2 UK: Caister Academic Press.

Longbottom, D., Livingstone, M., Maley, S., Van der Zon, A., Rocchi, M., Wilson, K., ... Buxton, D. (2013). Intranasal infection with Chlamydia abortus induces dose-dependent latency and abortion in sheep. PLoS ONE, 8(2), e57950. https://doi.org/10.1371/journal.pone.0057950

Merdja, S. E., Khaled, H., Aaziz, R., Vorimore, F., Bertin, C., Dahmani, A., ... Laroucau, K. (2015). Detection and genotyping of Chlamydia species responsible for reproductive disorders in Algerian small ruminants. Tropical Animal Health and Production, 47(2), 437-443. https://doi.org/10.1007/s11250-014-0743-x

Müller, U., Sachse, K., Kemmerling, K., Rietz, C., \& Sauerwein, H. (2013). Identification of certain management practices and health data associated with Chlamydia infection status in German dairy herds. 
Veterinary Journal, 197(3), 905-907. https://doi.org/10.1016/j.tvjl. 2013.06.003

Ostermann, C., Rüttger, A., Schubert, E., Schrödl, W., Sachse, K., \& Reinhold, P. (2013). Infection, disease, and transmission dynamics in calves after experimental and natural challenge with a Bovine Chlamydia psittaci isolate. PLoS ONE, 8(5), e64066. https://doi.org/10. 1371/journal.pone.0064066

Pantchev, A., Sting, R., Bauerfeind, R., Tyczka, J., \& Sachse, K. (2010). Detection of all Chlamydophila and Chlamydia spp. of veterinary interest using species-specific real time PCR assays. Comparative Immunology Microbiology and Infectious Diseases, 33(6), 473-484. https://doi. org/10.1016/j.cimid.2009.08.002

Polkinghorne, A., Borel, N., Becker, A., Lu, Z. H., Zimmermann, D. R., Brugnera, E., ... Vaughan, L. (2009). Molecular evidence for chlamydial infections in the eyes of sheep. Veterinary Microbiology, 135, 142-146. https://doi.org/10.1016/j.vetmic.2008.09.034

Qin, S.Y., Yin, M.Y., Cong, W., Zhou, D.H., Zhang, X.X., Zhao, Q., .. Qian, A.D. (2014). Seroprevalence and Risk Factors of Chlamydia abortus Infection in Tibetan Sheep in Gansu Province, Northwest China. The Scientific World Journal, 2014, 6. ID 193464.

Rekiki, A., Thabti, F., Dlissi, I., Russo, P., Sanchis, R., Pepin, M., ... Hammami, S. (2004). Seroprevalence survey of major infectious abortive diseases in small ruminants in Tunisia. Revue de Médecine Vétérinaire, 156(7), 395-401.

Rodolakis, A. (2006). Chlamydiose et fièvre Q, similitudes et différences entre ces deux zoonoses. In: Proc. of Rencontres Recherches Ruminants, 6-7 décembre 2006, Paris, France: Institut de l'Élevage - INRA, 2006. Rencontres Recherche Ruminants, 13, 395-402.

Rogan, W. J., \& Gladen, B. (1978). Estimating prevalence from the results of a screening test. American Journal of Epidemiology, 107, 71-76. https://doi.org/10.1093/oxfordjournals.aje.a112510

Ruhl, S., Casson, N., Kaiser, C., Thoma, R., Pospischil, A., Greub, G., \& Borel, N. (2009). Evidence for Parachlamydia in bovine abortion. Veterinary Microbiology, 135, 169-174. https://doi.org/10.1016/j.vet mic.2008.09.049

Szymańska-Czerwińska, M., Niemczuk, K., \& Galińska, E. M. (2013). Serological and nested PCR survey to determine the occurrence of
Chlamydia infections in the Polish cattle population. Annals of Agricultural and Environmental Medicine, 20(4), 682-686.

Thomas, R., Davison, H. C., \& Wilsmore, A. J. (1990). Use of the IDEIA ELISA to detect Chlamydia psittaci (ovis) in material from aborted fetal membranes and milk from ewes affected by ovine enzootic abortion. British Veterinary Journal, 146(4), 364-367. https://doi.org/ 10.1016/S0007-1935(11)80031-X

Wheelhouse, N., Coyle, C., Barlow, P. G., Mitchell, S., Greub, G., Baszler, T., ... Longbottom, D. (2014). Waddlia chondrophila infects and multiplies in ovine trophoblast cells stimulating an inflammatory immune response. PLoS ONE, 9(7), e102386. https://doi.org/10.1371/journal. pone.0102386

Wilson, K., Sammin, D., Harmeyer, S., Nath, M., Livingstone, M., \& Longbottom, D. (2012). Seroprevalence of chlamydial infection in cattle in Ireland. Veterinary Journal, 193(2), 583-585. https://doi.org/10.1016/ j.tvjl.2011.12.018

Yoo, H. S. (2010). Infectious cause of reproductive disorders in cattle. Journal of Reproduction and Development, 56, 53-60. https://doi.org/ 10.1262/jrd.1056S53

Zaibet, L., Hammami, S., \& Jabbar, M. (2009). Sustainability of small ruminant production systems in Tunisia: A health marketing approach. Discussion Paper No. 17. ILRI (International Livestock Research Institute), Nairobi, Kenya. pp 138

Zhou, D. H., Zhao, F. R., Xia, H. Y., Xu, M. J., Huang, S. Y., Song, H. Q., \& Zhu, X. Q. (2013). Seroprevalence of chlamydial infection in dairy cattle in Guangzhou, southern China. Irish Veterinary Journal, 66, 2. https://doi.org/10.1186/2046-0481-66-2

How to cite this article: Barkallah M, Jribi H, Ben Slima A, et al. Molecular prevalence of Chlamydia and Chlamydia-like bacteria in Tunisian domestic ruminant farms and their influencing risk factors. Transbound Emerg Dis. 2017;00:1-10. https://doi.org/10.1111/tbed.12757 